\title{
Using AgMIP Regional Integrated Assessment Methods to Evaluate Vulnerability, Resilience and Adaptive Capacity for Climate Smart Agricultural Systems
}

\author{
John M. Antle, Sabine Homann-KeeTui, Katrien Descheemaeker, \\ Patricia Masikati, and Roberto O. Valdivia
}

\begin{abstract}
The predicted effects of climate change call for a multi-dimensional method to assess the performance of various agricultural systems across economic, environmental and social dimensions. Climate smart agriculture (CSA) recognizes that the three goals of climate adaptation, mitigation and resilience must be integrated into the framework of a sustainable agricultural system. However, current methods to determine a systems' ability to achieve CSA goals are lacking. This paper presents a new simulation-based method based on the Regional Integrated Assessment (RIA) methods developed by the Agricultural Model Inter-comparison and Improvement Project (AgMIP) for climate impact assessment. This method combines available data, field- and stakeholder-based surveys, biophysical and economic models, and future climate and socio-economic scenarios. It features an integrated farm and household approach and accounts for heterogeneity across biophysical and socioeconomic variables as well as temporal variability of climate indicators. This method allows for assessment of the technologies and practices of an agricultural system to achieve the three goals of CSA. The case study of a mixed crop livestock system in western Zimbabwe is highlighted as a typical smallholder agricultural systems in Africa.
\end{abstract}

\footnotetext{
J.M. Antle $(\triangle)$

College of Agricultural Sciences, Oregon State University, Corvallis, OR, USA

e-mail: john.antle@ oregonstate.edu

R.O. Valdivia

Department of Applied Economics, Corvallis, OR, USA

S. Homann-KeeTui

International Crops Research Institute for the Semi-Arid Tropics, Bulawayo, Zimbabwe

K. Descheemaeker

Wageningen University, Wageningen, Netherlands

P. Masikati

World Agroforestry Centre, Lusaka, Zambia
} 


\section{Introduction}

One of the most important challenges for agricultural researchers is to evaluate the potential adoption and impact of agricultural technologies. Early research focused on economic impacts, but the search for more sustainable systems has shown the need for multi-dimensional assessments that consider agricultural system performance in economic, environmental and social dimensions and the inevitable tradeoffs among those dimensions (Antle 2011; Antle et al. 2014). The emerging reality of climate change means that the search for sustainable systems must also consider vulnerability to climate change, which may include increasing frequency and magnitude of climate extremes. The recent calls for "climate smart" agriculture recognize that climate adaptation, mitigation and resilience must be integrated into the broader agenda of developing sustainable agricultural systems.

As Lipper et al. (2014) emphasize, climate-smart agriculture (CSA) is an approach for transforming and reorienting agricultural systems to support food security under climate change. Part of that process of re-orientation is to evaluate the performance of existing farming systems, and possible modifications of those systems, under a changing climate as well as with other changes (e.g., policy and technology) that may affect agricultural system performance and farm household well-being. Various elements of climate-smart agricultural systems have been identified, and a number of metrics can be utilized to evaluate systems for climate-smart attributes (Rosenzweig et al. 2015 and Rosenzweig et al. 2016).

Evaluating technologies for their performance in the multiple dimensions of sustainability poses major conceptual, analytical and data challenges: evaluating the farming system and farm household as an integrated unit, rather than individual production activities; linking the farming system to the other environmental and social outcomes that it may impact, including greenhouse gas emissions and carbon sequestration; and evaluating performance in more extreme and possibly variable climate conditions. Furthermore, there is a need to assess the usefulness of prospective changes in production systems that are not yet in widespread use, as well as the use of existing or new technologies under future climate and socio-economic conditions (Antle et al. 2015a).

The goal of this article is to describe and demonstrate the use of new simulationbased methods to evaluate the potential for currently available or prospective agricultural systems to achieve the goals of CSA. The motivation for this approach is the fact that conventional field experiments and ex post assessments are not appropriate tools to evaluate agricultural system performance in changing and uncertain climatic conditions and future socio-economic conditions. The approach presented here combines the available data, including observational data from field experiments and from surveys of actual farming system performance, with biophysical and economic models and future climate and socio-economic scenarios. These models become the "laboratory" in which simulation experiments are conducted to explore the performance of agricultural systems under the range of conditions considered relevant by stakeholders and scientists. An important feature and strength of 
this method is that it relies on input from stakeholders and thus provides a process to effectively engage stakeholders in the development and evaluation of technological options (Valdivia et al. 2015).

The approach we present is based on the Regional Integrated Assessment (RIA) methods developed by the Agricultural Model Inter-comparison and Improvement Project (AgMIP) for climate impact assessment (Antle et al. 2015b; AgMIP 2015). In this chapter, we first describe some of the key features of smallholder farming systems typical in many parts of Africa as well as other parts of the world, focusing in particular on the smallholder systems that involve rainfed crops and livestock and that are particularly vulnerable to climate and other changes and also have limited capacity to adapt to such changes. Next we provide an overview of the AgMIP methods for technology impact assessment, and discuss how they can be used for CSA assessments of vulnerability, resilience and adaptive capacity. We illustrate the application of these methods with a case study of crop-livestock systems in Zimbabwe. We conclude with a discussion of the strengths and limitations of these methods, and how they could be improved to be more useful for CSA.

\section{Key Features of Crop-Livestock Systems: Implications for Modeling}

To motivate the discussion of methods to follow, we first describe key features of typical smallholder agricultural systems in Africa, using the example of mixed crop livestock systems found in the Nkayi district of western Zimbabwe. Crop production is rainfed, and average annual rainfall ranges from 450 to $650 \mathrm{~mm}$, making the system vulnerable to erratic rainfall with a drought frequency of one in every 5 years. Long-term average maximum and minimum temperatures are 26.9 and $13.4{ }^{\circ} \mathrm{C}$, respectively. The soils vary from inherently infertile deep Kalahari sands, which are mainly nitrogen- and phosphorus-deficient, to clay and clay loams that are also nutrient-deficient due to continuous cropping without soil replenishment. Farmers use mainly a mono-cereal cropping system with addition of low amounts of inorganic and organic soil amendments. Natural pasture provides the main feed for livestock, and biomass availability is seasonal. During the wet season feed quantity and quality is appreciable, while during the dry season there is low biomass of poor quality. The natural pastures are mainly composed of savannah woodlands, with various grass species (Homann et al. 2007; Masikati et al. 2015).

As in many parts of Africa, mixed crop-livestock production systems are dominant in Nkayi. These farming systems are mainly based on maize, with smaller portions of sorghum, groundnuts, and cowpeas as staple crops, combined with the use of communal range lands, fallow land, and crop residues for livestock production (Fig. 1). Household livestock holdings vary from a few to 40 head per household of cattle, donkeys, and goats. Livestock offer opportunities for risk spreading, farm diversification, and intensification, and provide significant livelihood benefits 


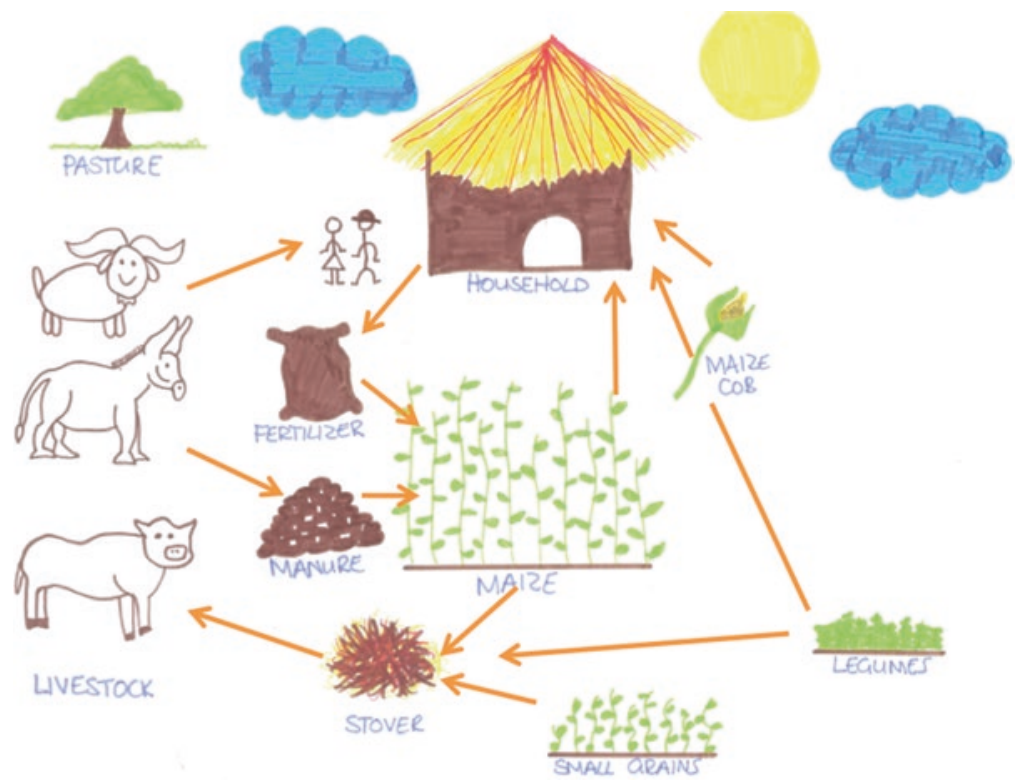

Fig. 1 Mixed crop livestock farming systems, provider of food and livelihoods, and most common form of land use, affected by climate change in semi-arid Zimbabwe (Figure 2 of Masikati et al. 2015)

(Bossio 2009; Williams et al. 2002). Animals complement cropping activities through the provision of manure for soil fertility maintenance, draft power for cultivation, transport, cash, and food, while crop residues are used as adjuncts to dryseason feed. These systems evolve in response to various interrelated drivers, such as increased demographic pressure along with higher incomes earned by the urban populations, which results in a growing demand for crop and livestock products with the development of local and urban markets (Homann-KeeTui et al. 2013). This increased demand for crop and livestock products could benefit small-scale farmers as they gain access to markets, if they are able to intensify and diversify production in a sustainable way. These diverse income sources could reduce risk and increase resilience of farmers.

Another key characteristic of crop-livestock systems in many regions of Africa is low productivity due to a combination of factors that include unfavorable climatic conditions, poor and depleted soils, environmental degradation, and low level of capital endowment that leads to limited uptake of improved technologies, as well as adverse policies (Kandji et al. 2006; Morton 2007; World Bank Report 2009). Climate variability and change stressors, superimposed on the many structural problems in smallholders farming systems where there is not much support nor adequate adaptation strategies, can exacerbate food insecurity and increase vulnerability (Kandji et al. 2006; Morton 2007). 
These characteristics of smallholder farming systems suggest that assessment models need the following features and capabilities.

Integrated farm and household approach A whole-farm approach is needed to represent all possible adaptation and mitigation options, including crop-livestock interactions and nutrient cycling, effects of specialization and diversification, and scale effects. In addition, a whole farm and household approach is needed to represent all components of the household's income, including both on-farm and offfarm income sources and employment opportunities. The household approach is also needed to represent economic vulnerability and resilience, for example, offfarm income may be impacted differently than farm income by climate change.

Bio-physical and socio-economic heterogeneity Analysis must account for the heterogeneity that is often high in farm household populations, in terms of soil conditions and climate, as well as differences in farm and herd size, behavioral differences due to the farm decision makers' knowledge and experience, the age, gender and health of the farm household members, and location and access to markets, capital and information.

Temporal variation and system dynamics Temporal variation in inputs and outputs of these systems has important effects on system performance and human wellbeing. For example, a key element of food security is the stability of food availability over the annual cycle. Adaptation, mitigation and resilience all involve change over time that can be thought of as investment or dis-investment in natural capital (e.g., soil fertility), physical capital (tools, machinery and structures, as well as livestock), human capital (farm family members' health, education and knowledge), and social capital (social networks and relationships). Resilience involves the capacity of a system to withstand a shock or disruption and naturally involves an understanding of system dynamics.

\section{AgMIP Regional Integrated Assessment Methods}

AgMIP has developed a methodology for RIA of climate change impact, adaptation, mitigation and vulnerability, and thus provides a framework for CSA assessment. The approach is designed to quantify indicators of system performance deemed to be relevant by both stakeholders and scientists, and then conduct simulation experiments to evaluate how system performance responds to climate and other changes, including system changes for climate adaptation and mitigation. These methods can be used in various ways to support technology development, e.g., to facilitate the targeting of agricultural interventions to farm types, for design and impact assessment of context specific safety-net, food security or market oriented intervention packages. 
Based on discussions with stakeholders and the research assessment literature, a number of key indicators were identified to assess impact, vulnerability, mitigation and adaptation. These indicators are also relevant to the evaluation of CSA.

- Physical quantities and value of principal agricultural products, at the farm household level and aggregated to the regional or population level.

- Net value of single agricultural commodities as well as entire farms

- Average household per-capita income or wealth.

- The headcount poverty rate in the population (i.e., the proportion of households below the poverty line) and other poverty measures such as the poverty gap (i.e., the degree to which individuals are below the poverty line).

- Food security indicators, including capability to buy an adequate diet, per-capita food consumption, calories and other nutrient intake, dietary diversity indicators, and impacts on children such as stunting or mortality.

- Environmental indicators, including soil fertility, soil erosion, and indicators of greenhouse gas emissions and mitigation.

- Vulnerability, defined as the proportion of households that may be adversely affected by climate change. Losses can be measured in economic terms or in other dimensions of well-being such as health.

- Resilience, defined as the capability of a system to minimize the magnitude of adverse impacts or enhance positive effects towards greater adaptive capacity.

The foundation of the AgMIP RIA approach is the design of the simulation experiments that are used to evaluate climate impacts and the effects of system adaptations. There are many possible simulation experiments that can be carried out. Working with various stakeholders, AgMIP has identified four "core" research questions for regional integrated assessments. Figure 2 illustrates these Core Questions described below. Note that climate change can have either negative (left figure) or positive (right figure) effects without adaptation, and in a given population of farm households some may experience negative effects and some may experience positive. Effective climate adaptations will reduce negative effects or enhance positive effects. Another key element of Fig. 2 is that the climate assessment is carried out in the context of a plausible future state of the world (i.e., the non-climate biophysical and socio-economic future conditions) embodied in a "representative agricultural pathway" or RAP. As we discuss further below, the AgMIP RIA method includes the development of RAPs with inputs from scientists as well as stakeholders.

The four core questions are defined as follows:

Core Question 1: What is the sensitivity of current agricultural production systems to climate change? This question addresses the isolated impacts of a change in climate assuming that the production system does not change from its current state. It is useful as a baseline for comparison with other combinations of technology and states of the world.

Core Question 2: What are the effects of adaptation in the current state of the world? This question is one often raised by stakeholders: what is the value of 

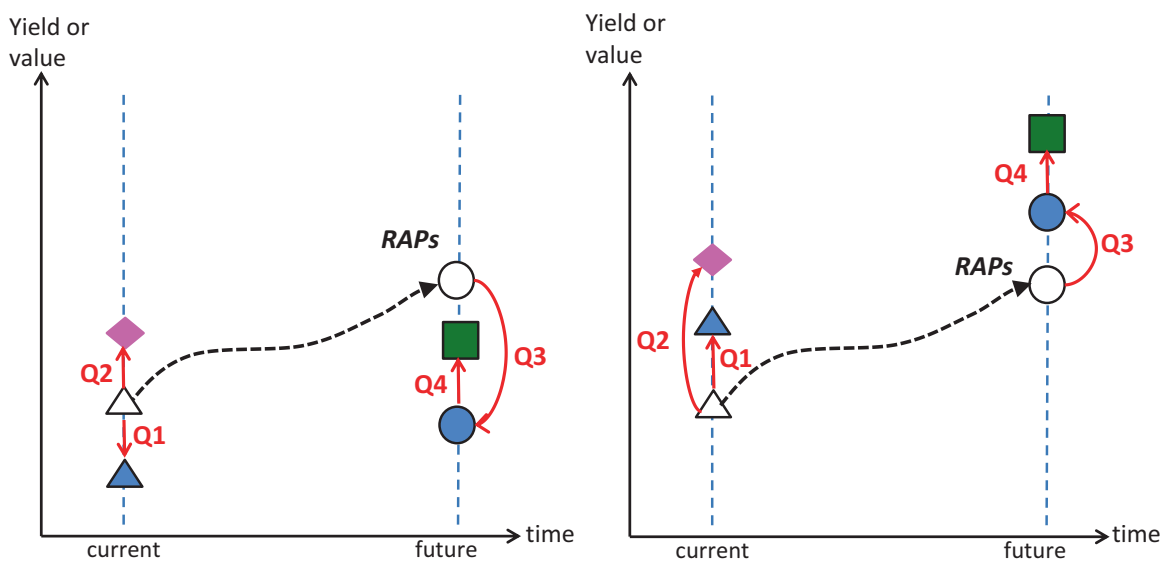

Fig. 2 Overview of core climate assessment questions and the production system states that are simulated. The dashed black line represents the evolution of the production system in response to development in the agricultural sector that would occur without climate change, or independently of climate change, as defined by a Representative Agricultural Pathway $(R A P)$. Arrows illustrate effects associated with the four core questions described in the text (Source: adapted from Antle et al. 2015b)

adapting today's agricultural systems to climate changes that may be occurring now and in the near future?

Core Question 3: What is the impact of climate change on future agricultural production systems? This question evaluates the isolated role of climate impacts on a future production system, which will differ from the current production system due to development in the agricultural sector not directly motivated by climate changes.

Core Question 4: What are the benefits of climate change adaptations? This question analyzes the benefit of potential adaptation options in the production system of the future, which may offset climate vulnerabilities or enhance positive effects identified in Core Question 3 above.

The AgMIP RIA methodology is designed to enable research teams, in collaboration with stakeholders, to answer each of these core questions. Figure 3 provides an overview of the approach. As noted in the previous section, an integrated wholefarm and household modeling approach is needed for CSA. Accordingly, the AgMIP approach to RIA is built on the concept of the farm household and the farming system that it uses. The foundation of the AgMIP approach is the characterization of the existing farming system, typically by developing "cartoons" or system diagrams (see Fig. 1, and Fig. 3b). The research team uses this characterization of the current systems to identify the key system components, and the corresponding data and models that will be needed to implement the RIA analysis. 


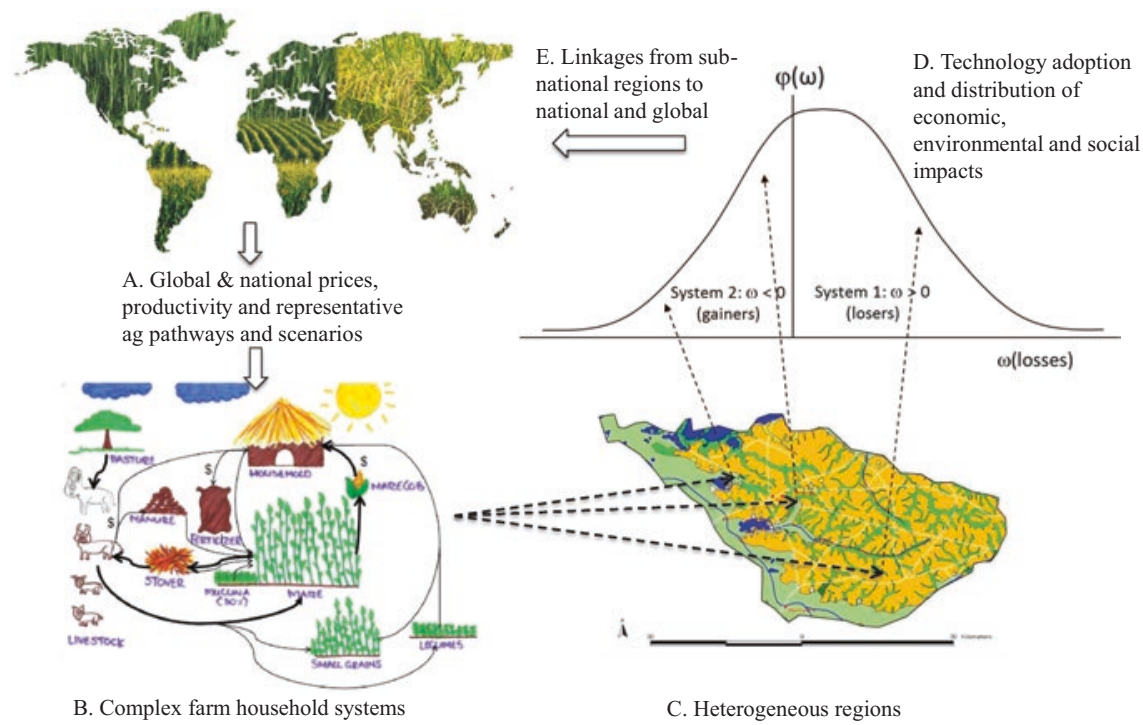

Fig. 3 AgMIP Regional Integrated Assessment approach simulates climate change impact, vulnerability and adaptation through climate data, bio-physical simulation models and economic models representing a population of heterogeneous farm household systems. (a) RAPS together with global and national price, productivity and land use projections define the bio-physical and socio-economic environment in which (b) complex farm household systems operate in heterogeneous regions (c). Analysis of technology adoption and impact assessment is implemented in these heterogeneous farm household populations $(\mathbf{d})$. This regional analysis may feed back to the country and global scales (e) (Source: Antle et al. 2015a)

In the AgMIP RIA methodology, the heterogeneous response to climate change derives from the productivity impacts of climate change incorporated in the model through crop and livestock simulation models, as well as the socio-economic heterogeneity in the farm household system due to variations in farm size, household size, and non-farm income. As explained in detail in the AgMIP RIA Handbook (AgMIP 2015), the AgMIP method uses crop and livestock model simulations to project the effects of climate change on the productivity of a system. In this method a yield under a changed climate is approximated as $\mathrm{y}^{\mathrm{c}}=\mathrm{r}^{\mathrm{c}} \cdot \mathrm{y}^{\mathrm{o}}$ where $\mathrm{y}^{\mathrm{o}}$ is an observed yield and $r^{c}$ is a simulated relative yield calculated as $r^{c}=y^{s c} / y^{s o}$, where $y^{\text {sc }}$ is the simulated yield under the changed condition, and $\mathrm{y}^{\mathrm{so}}$ is the simulated yield under the observed condition. This procedure is used rather than directly using $\mathrm{y}^{\mathrm{sc}}$ as an estimate of $y^{c}$ to account for the fact that simulated yields do not incorporate all the factors affecting observed yields and thus tend to be biased. If this bias is (approximately) proportional and equal for both $\mathrm{y}^{\mathrm{sc}}$ and $\mathrm{y}^{\mathrm{so}}$ then it will cancel out. In cases where process-based models are not available for a crop or livestock species, assumptions for yield impacts are included in scenarios based on expert judgment and other available data such as behavior of similar species or studies of analog climates. 
For analysis of adaptations, a similar method is used to assess how the existing system could be changed. These changes can range from management of the existing production activities, changes in the land or other resources allocated to those activities, as well as the introduction of new activities or the elimination of activities. Also, changes in the farm household's labor allocation between production activities, and between agricultural and non-agricultural activities can be considered. These characterization of the existing and prospective farming systems also helps to develop future socio-economic pathways (i.e., Representative Agricultural Pathways, see below) by identifying the "external" or "driving" variables that define the bio-physical and socio-economic conditions in which the analysis is conducted. For example, if the analysis is being designed for a future period, it is likely that prices received or paid by the farmers will be different. It is also likely that characteristics of the farm household population will change, such as the farm size distribution, non-agricultural income and household size.

\subsection{Quantifying Vulnerability}

The AgMIP RIA methods are designed to assess vulnerability of farm households to climate change. We define a climate as a probability distribution of weather events that occur at a specific place and during a defined period of time. A change in climate is a change in the probability distribution of weather events. These changes are often described in terms of the mean temperature over a period of time such as a day, month or year, but can also be changes in temperature extremes, the variability of weather events, and other aspects such as rainfall amount and intensity and wind velocity.

Impacts of climate change are quantified as gains and losses in economic wellbeing (e.g., farm income or per capita income) or other metrics of well-being (e.g., changes in health or environmental quality). In this framework, some or all individuals may gain or lose from a change, and we say the losers are vulnerable to loss from climate change. The AgMIP RIA methodology is designed to quantify the proportion of the population that are losers, as well as the magnitude of loss. It is important to note, however, that in a heterogeneous population there are typically some gainers and some losers, and thus the net impact may be positive or negative.

The AgMIP RIA method is designed to quantify climate vulnerability by modeling a heterogeneous population of farm households rather than modeling a "representative" or average or typical farm. This approach begins with the representation of impacts on the farm household using the concept of economic gains and losses (other metrics of impact can be also be used depending on available data, e.g., the impact on health of household members). As Fig. 3 shows, the AgMIP RIA approach uses a statistical representation of the farming system in a heterogeneous region or population to quantify the distribution of gains and losses, e.g., due to climate change. Figure 4 illustrates this idea with two loss distributions. The area under the distribution on the positive side of zero is the proportion of losers and is the measure 


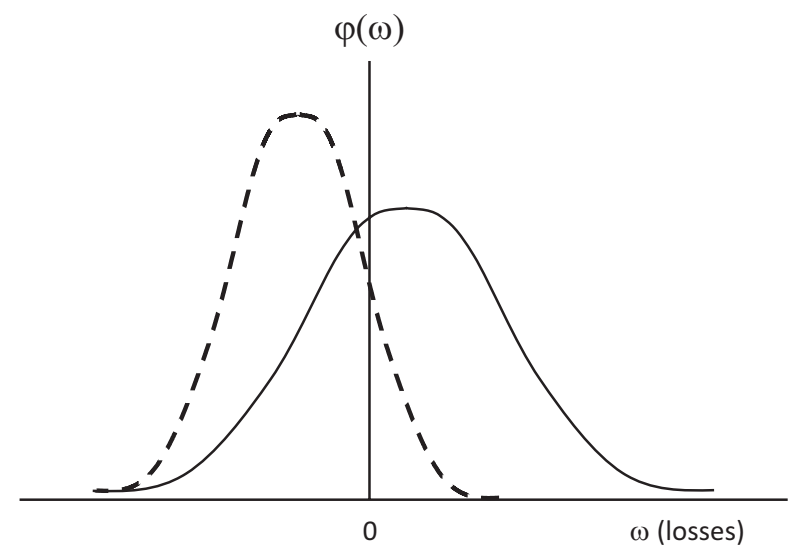

Fig. 4 Vulnerability Assessment Using the Distribution of Losses Associated with Climate Change. The area under the distribution on the positive side of zero is the proportion of losers and a measure of vulnerability. Here the solid distribution represents a system for which the average loss is positive and there are more losers than gainers. The dashed distribution represents a system with more gainers than losers. The goal of climate adaptation is to shift the distribution leftward

of vulnerability. The solid distribution in Fig. 4 represents a system for which the average loss is positive and there are more losers than gainers. Note, however, that even in this case there are some gainers.

The goal of analysis for CSA is to improve the performance of farming systems. In the context of vulnerability analysis, this means reducing the number of losers (the vulnerable) and increasing the gainers from any perturbation of the system, be it climate change or any other change. The dashed distribution in Fig. 4 represents a system that is less vulnerable to climate change, and has more gainers than losers. Note that in this case, even though gainers outnumber losers, there are still some losers. It is also important to note that both the mean and the dispersion of the distribution of gains and losses matters to the measurement of vulnerability. Indeed, the dispersion (i.e., variance) of the distribution of losses represents the heterogeneity of the impacts of climate change on the population. In the AgMIP RIA methodology, this heterogeneous response to climate change derives from the productivity impacts of climate change incorporated in the model through crop and livestock simulation models (see discussion below), as well as the socio-economic heterogeneity in the farm household system due to variations in farm size, household size, and non-farm income. The areas under the distributions on the positive side in Fig. 4 represent the proportion of vulnerable farm households. The AgMIP RIA methodology also provides the capability to simulate the magnitude of impacts on the vulnerable members of the population, as well as the impact on those that gain, and the net or aggregate impact in the population. 


\subsection{Quantifying Resilience}

Resilience has been defined in a number of ways in the scientific literature. In ecology, resilience is defined as the capacity of a system to maintain its form and function in response to a shock or disruption (Folke 2006; Nelson et al. 2007). In economic terms, resilience can be defined as the capacity to restore or maintain economic values, such as farm income (Antle et al. 2006; Antle and Capalbo 2010), or to minimize the loss from an adverse disruption or "disaster" over the time it takes for a system to return to its "normal" state (Hallegate 2014). Resilience to climate change can also be defined more broadly as the capacity to cope with change and minimize losses from change and enhance possible benefits of change, and thus can incorporate longer-term responses through adaptation (Malone 2009).

The definition of resilience as the capacity to withstand disruptions refers to the properties of a given system's performance, and is most relevant to analysis of relatively short-term events such as a storm or drought where it can be expected that the system will return to its normal state. In contrast, the capability to adapt or respond by making purposeful changes in a system seems most relevant to longer-term permanent changes in climate, and can include adaptations that are designed to improve the capability to withstand shocks or disruptions. Clearly, both concepts of resilience - the ability to minimize the effects of temporary shocks and disruptions, as well as the capacity to cope with the long-term shifts in weather patterns associated with climate change - are relevant to analysis of agricultural system performance.

The AgMIP RIA framework illustrated in Figs. 2 and 3 can be used to quantify resilience using the various indicators identified above. As noted above, vulnerability is measured as the proportion of farm households that experience a loss over a specified period of time. Loss can be measured in economic terms as reduced income or loss of the capitalized value of income plus assets, and also in noneconomic terms such as reduced health or degraded environmental conditions. To see how resilience can be quantified, define the minimum possible loss for a given

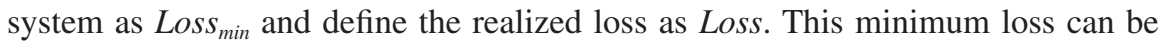
measured in various ways depending on the context. For example, it could be the loss that would be incurred if the best coping actions are undertaken as soon as possible and as effectively as possible. A resilience indicator can be calculated as 100 (Loss $_{\text {min }}$ / Loss), similar to what Hallegate (2014) defines as "microeconomic resilience". Thus, if a system can achieve the minimum possible loss its resilience is $100 \%$, and otherwise its resilience is less than $100 \%$.

This measure of resilience fits the situation where there is a loss, whereas with climate change and other types of change there can be net aggregate gains in some cases, and even when there are losers, there are also likely to be some gainers. To accommodate both gains and losses, we adopt the convention that resilience is $100 \%$ for gainers. Letting $v$ be the percent of vulnerable population, the resilience indicator for the population of gainers and losers is then calculated as $100(1-v)+v$ Loss $_{\text {min }} /$ Loss. 


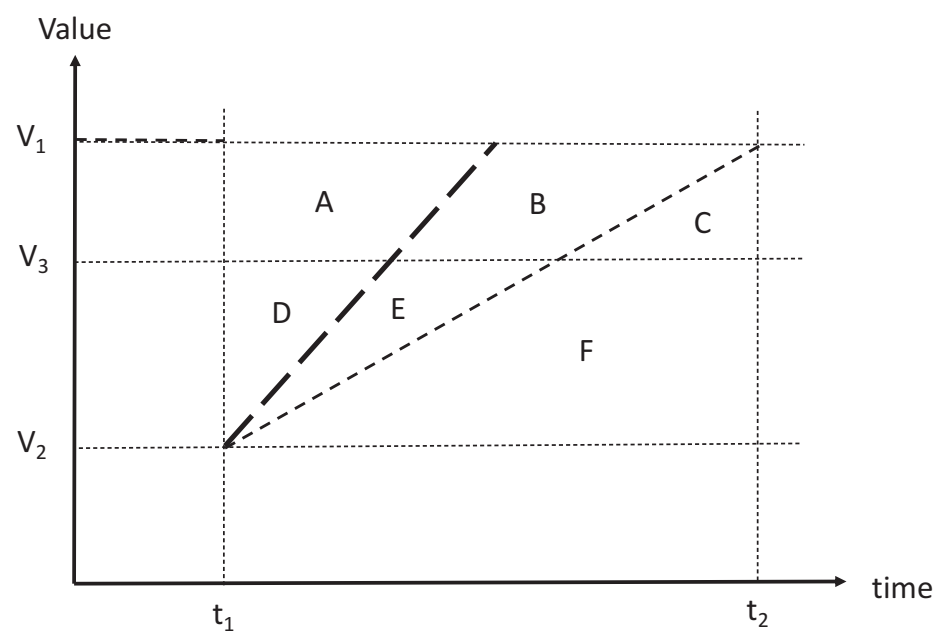

Fig. 5 Analysis of Resilience to Temporary Disruptions and Long-term Change. See the text for explanation

This definition of resilience makes sense for a temporary change or disruption that a system can fully recover from, such as a seasonal drought followed by normal weather. However, if there are long-term changes, such as climate change, then the minimum loss would grow over time and the ratio Loss $_{\min } /$ Loss would be undefined. A solution to this problem is to measure the losses over a finite time period relevant to decision making for making technology investment decisions, so that the minimum loss and actual loss are both bounded.

Figure 5 provides a stylized graphical representation of how resilience can be quantified for a temporary disruption as well as for a permanent change, over a specified time horizon from time $t_{1}$ to time $t_{2}$. In the analysis of a temporary disruption, the system provides a value $\mathrm{V}_{1}$ before the disruption occurs at $\mathrm{t}_{1}$. The disruption lowers the system performance to $\mathrm{V}_{2}$, and the system then recovers along some path from $V_{2}$ back to $V_{1}$ (the path is shown as linear in Fig. 5, but more generally may be nonlinear). Suppose we are comparing two different systems, one more resilient than the other. The heavy dashed line in Fig. 5 indicates the system with the most rapid recovery possible, and thus Loss $_{\min }$ equals area $(\mathrm{A}+\mathrm{D})$ and its resilience is $100 \%$ The less resilient system recovers along the path indicated by the lighter dashed line, so the loss is area $(\mathrm{A}+\mathrm{B}+\mathrm{D}+\mathrm{E})$, and the system resilience is calculated as $100(\mathrm{~A}+\mathrm{D}) /(\mathrm{A}+\mathrm{B}+\mathrm{D}+\mathrm{E})<100 \%$.

The analysis of resilience to a long-term change in climate is somewhat different than the case of a temporary disturbance in several respects. In response to longterm changes we expect systems to be adapted to climate change to some degree. There are three types of adaptations that can be expected to occur and can overlap at different scales. First, there are the kinds of changes in management that farmers can undertake within the existing system, such as changes in planting dates and 
reallocation of land and other resources among existing crops and livestock activities, or reallocation of their time among farm and non-farm activities. These types of adaptations have been called "autonomous or incremental adaptations." Second, there are adaptations that require investments external to the farm, such as investments in research and development of new technologies, such as improved crop varieties, or diversification and risk management options, sometimes referred to as "planned or systems adaptations." Third, transformational adaptation requires more fundamental changes in production systems, institutional arrangements, priorities for investment, and norms and behaviour (Kates et al. 2012). Zimbabwe is among the countries where transformational adaptation is recommended, to shift the systems towards more livestock-oriented and diversified systems with drought-tolerant food and feed crops, and development of the associated value chains (Rippke et al. 2016; Rickards and Howden 2012).

As illustrated in Fig. 2, the system currently in use would follow a path over time from the value indicated by the white triangle to the blue circle, whereas a system better adapted to the future climate would achieve a higher level of performance indicated by the green square. However, it is not clear from this diagram at what point in time along this path adaptations take place. One might assume that autonomous adaptations occur more-or-less continuously as farmers learn about climate changes and how to adapt management, whereas planned adaptations could occur in more discrete steps, e.g., as new crop varieties are developed and released.

The complexity of the progression of adaptation over time creates a major challenge for the analysis of adaptation. Given the difficulty analysts face in knowing how adaptations would evolve over time, the approach we adopt here is to treat each adapted system as if it were to become available at a discrete point in time, and that its effectiveness increases over time up to its maximum, depending on the characteristics of the technology and the capacity of farmers to acquire and use it successfully.

Following this approach, in Fig. 5 we can interpret $V_{1}$ as the performance of the current system in the future period without climate change (i.e., as the value represented by the white circle in Fig. 2). $V_{2}$ represents the value the same system would achieve with climate change (i.e., the blue circle in Fig. 2), and $\mathrm{V}_{3}$ represents the value that an adapted system can achieve (i.e., the green square in Fig. 2). We can now interpret the heavy dashed line as a more rapid adoption pathway for the adapted technology, and the lighter dashed line as a less-rapid adoption pathway. Thus, under the rapid adaptation scenario, the loss due to climate change from $t_{1}$ to $\mathrm{t}_{2}$ would be equal to area $(\mathrm{A}+\mathrm{B}+\mathrm{C}+\mathrm{D})$ which we could interpret as Loss $_{\min }$ and corresponding to a resilience measure of $100 \%$. Under the slower adaptation pathway, the loss would be $(A+B+C+D+E)$, implying a resilience of 100 $(\mathrm{A}+\mathrm{B}+\mathrm{C}+\mathrm{D}) /(\mathrm{A}+\mathrm{B}+\mathrm{C}+\mathrm{D}+\mathrm{E})<100 \%$. The resilience of the unadapted system would be lower, and equal to $100(\mathrm{~A}+\mathrm{B}+\mathrm{C}+\mathrm{D}) /(\mathrm{A}+\mathrm{B}+\mathrm{C}+\mathrm{D}+\mathrm{E}+\mathrm{F})$. 


\subsection{Representing Future Socio-economic Conditions}

In a climate change analysis, it is necessary to distinguish between three basic factors affecting the expected value of a production system: the production methods used (i.e., the system technology); the physical environment in which the system is operated, including soils and climate; and the economic and social environment in which the system is operated, i.e., the socio-economic setting. In the AgMIP RIA methodology, the non-climate bio-physical conditions and socio-economic conditions are embodied in a Representative Agricultural Pathway, or RAP (Valdivia et al. 2015). RAPs are qualitative storylines that can be translated into model parameters such as farm and household size, prices and costs of production, and policy. Following the four core climate impact assessment questions discussed above, the model can be set up with appropriate combinations of parameters to represent the corresponding technologies, climates, and socio-economic conditions.

As indicated in Fig. 2, the analysis of Core Questions 3 and 4 is carried out under plausible future conditions defined by Representative Agricultural Pathways. To project the average level of productivity into the future that would occur with ongoing technological advancements (not associated with climate change or adaptation), the AgMIP methodology utilizes the technology trend and price projections developed for global economic models (e.g., see Nelson et al. 2013), together with the assessment of technology trends made by research teams in the development of regional RAPs.

\subsection{Defining and Quantifying Adaptation}

The goal of adaptation analysis is to improve the performance of farming systems, e.g., to reduce vulnerability as illustrated in Fig. 4. The relative yield concept discussed above for modeling climate productivity impacts can also be applied to quantify the effects of an adaptation on a crop yield. Let a yield for an adapted system (say, a change in planting date) be $\mathrm{y}^{\mathrm{a}}=\mathrm{r}^{\mathrm{a}} \cdot \mathrm{y}^{\mathrm{o}}$ where $\mathrm{y}^{\mathrm{o}}$ is an observed yield and $\mathrm{r}^{\mathrm{a}}$ is a simulated relative yield calculated as $\mathrm{r}^{\mathrm{a}}=\mathrm{y}^{\mathrm{sa}} / \mathrm{y}^{\mathrm{so}}$, where $\mathrm{y}^{\mathrm{sa}}$ is the simulated yield under the adapted management, and $\mathrm{y}^{\mathrm{so}}$ is the simulated yield under the nonadapted (observed) management. This method can be applied under any climate conditions. Thus, for projecting yield with climate change and adapted management, we have $\mathrm{y}^{\mathrm{ac}}=\mathrm{r}^{\mathrm{a}} \cdot \mathrm{y}^{\mathrm{c}}=\mathrm{r}^{\mathrm{a}} \cdot \mathrm{r}^{\mathrm{c}} \cdot \mathrm{y}^{\mathrm{o}}$.

As we discussed above, the analysis of climate impact and adaptation must be carried out under future socio-economic conditions defined by a RAP. By definition, the RAP represents changes in socio-economic conditions that would occur without climate change. Therefore, any changes in crop or livestock systems and productivity described in a RAP cannot be a climate adaptation. Changes defined as a climate adaptation must, by definition, be changes that would occur in response to changes in climate, given any other changes that would have occurred regardless of climate 
change. The "simulation experiments" carried out for a climate adaptation analysis are designed to show the effect of climate adaptation holding all else constant, including any changes in productivity that would have occurred without climate change.

\section{Assessing Crop-Livestock System Adaptations in Zimbabwe for CSA}

In this section we summarize results from a recent study of the crop-livestock systems described in Fig. 1 and Section 1 that used the AgMIP integrated assessment approach to evaluate the climate vulnerability and benefits of adaptation strategies in these systems for multiple climate change scenarios (Masikati et al. 2015). Data from climate projections and RAPs were combined with soils and weather data and farm survey data to parameterize crop, livestock and economic simulation models to simulate the performance of systems under future socio-economic conditions with climate change. Next these models were used to simulate the performance of the systems with three adaptations that could improve crop and livestock productivity: applying higher levels of $\mathrm{N}$ fertilizer with micro-dosing; producing maize with recommended $\mathrm{N}$ fertilizer application rates; and with maize being grown in a rotation with mucuna.

To illustrate the use of the AgMIP RIA methods, here we report crop and livestock modeling results using averages over projections from five mid-century climate models that were run with a high emissions scenario (referred to by climate modelers as Representative Concentration Pathway 8.5), together with a business as usual Representative Agricultural Pathway for mid-century. We evaluate the economic impacts of the driest climate scenario on the crop-livestock system of Nkayi, Zimbabwe without adaptation, and with the following package of adaptations designed for resource-limited households.

- Adoption of long duration maize varieties instead of short duration varieties, with grain yield increases between $8 \%$ and $18 \%$, and residue increases between $5 \%$ and $11 \%$.

- Converting $1 / 3$ of the maize land to maize-mucuna rotation, $30 \%$ of the mucuna biomass left on the fields as inorganic fertilizer for subsequent maize. $70 \%$ fed to cattle or available for sale.

- Application of micro-dosing (17 kg N/ha) on 1/3 of the maize field, second year after the maize mucuna rotation.

It is important to emphasize that the results reported here are for a single scenario to illustrate how the AgMIP methods can be used for CSA analysis. Each of the components of the analysis is uncertain, and to represent that uncertainty a more complete analysis would utilize multiple climate projections and multiple socioeconomic scenarios and model components. Also, we emphasize that by interpreting 
these changes as climate adaptations, it is assumed that these changes would not have been adopted in order to achieve the productivity gains already embodied in the Representative Agricultural Pathway.

\subsection{Climate Projections}

For the climate scenario used, temperatures are projected to increase across the whole region of southern Africa. Changes range from large increases inland (above $3{ }^{\circ} \mathrm{C}$ in southwestern Botswana and surrounding areas) to smaller increases in coastal areas. Rainfall projections are less certain; rainy seasons are likely to start later and there are indications that rainfall will decrease over most of southern Africa, particularly over the western and central regions. Here we present results using one model that shows a mean temperature increase of about $3{ }^{\circ} \mathrm{C}$ and a mean rainfall decrease of about $0.6 \mathrm{~mm}$ /day over October-March, compared to the current average of about $3.4 \mathrm{~mm} /$ day.

\subsection{Crop Models}

The Agricultural Production Systems Simulator (APSIM) (Keating et al. 2003) was used to assess the impacts of climate change on crop production. The model was calibrated for maize and the forage legume, mucuna (mucuna pruriens) using onfarm experimental data obtained from the ICRISAT research work under different projects in Nkayi district (Masikati 2011; Homann-KeeTui et al. 2013). APSIM Results were judged satisfactory with observed mean maize grain yield of $1115 \mathrm{~kg} /$ ha and simulated of $1185 \mathrm{~kg} / \mathrm{ha}$. However, the model had a tendency to over-predict maize biomass with mean observed yield of $2460 \mathrm{~kg} / \mathrm{ha}$ and simulated of $3385 \mathrm{~kg} /$ ha. For mucuna biomass results were satisfactory with mean observed yields of $4263 \mathrm{~kg} / \mathrm{ha}$ and simulated of $4224 \mathrm{~kg} / \mathrm{ha}$.

The model was also evaluated for its ability to simulate maize grain yield variability across farming households. The model showed capacity to simulate the middle yield range from the farming households but did not perform so well for the lower and higher yields (Masikati et al. 2015). To offset the models' effects on projected future yields, the simulated yields were bias corrected before doing the economic analyses; the biomass yields were also adjusted before they were used for livestock simulations. 


\subsection{Livestock Model}

Household-level livestock production was modeled with LIVSIM (LIVestock SIMulator, Rufino et al. 2009). The LIVSIM model was earlier calibrated for Zimbabwean conditions and the Mashona breed, for which it is also used here (Rufino et al. 2008; Rufino et al. 2011). LIVSIM simulates production with a monthly time step, based on breed-specific genetic potential and feed intake, taking into account specific rules for herd management. The impact of climate change and the various adaptation strategies on livestock production was predicted based solely on simulated changes in on-farm feed production resulting from the crop model runs. Livestock rely on community rangelands during the whole year and in the dry season, crop residues constitute an important feedbase component (Masikati 2011). However, the feed quality of the crop residues and of the dried grasses in the rangeland is low and also the risk of low crop production during dry years is relatively high. Therefore, feed gaps in the dry season are common, leading to important inefficiencies in the livestock component of the system. Hence grass and on-farm feed production and composition change with climate, and the effects of these changes on livestock were simulated with LIVSIM for climate change under current practices and for the adaptation strategies. The effects of increased crop residue availability in the fertilizer adaptation strategies and of higher-quality feed in the mucuna strategy were investigated. However, potential changes in rangeland productivity and direct effects of temperature on animal performance were not taken into account in this study.

\subsection{Economic Model}

AgMIP is using the Tradeoff Analysis model for Multi-Dimensional impact assessment (TOA-MD) to implement the economic analysis component of the RIA methodology. The TOA-MD model is a parsimonious, generic model for analysis of technology adoption and impact assessment, and ecosystem services analysis. Further details on the impact assessment aspects of the model are provided in Antle (2011) and Antle et al. (2014). The model software and the data used in various studies are available to researchers with documentation and self-guided learning modules at http://tradeoffs.oregonstate.edu.

There are several features of this model that make it appropriate for assessment of technologies for climate impact assessment as well as analysis of technologies for CSA. First, TOA-MD represents the whole farm production system which can be composed of (as appropriate) a crop sub-system containing multiple crops, a 
livestock subsystem with multiple livestock species, an aquaculture sub-system with multiple species, and the farm household (characterized by the number of family members and the amount of off-farm income). Second, TOA-MD is a model of a farm population, not a model of an individual or "representative" farm. Accordingly, the TOA-MD model is designed to quantify vulnerability and resilience using gains and losses as discussed above. With suitable bio-physical and economic data, these statistical parameters can be estimated for an observable production system. Using the methods described in the AgMIP Regional Integrated Assessment Handbook (AgMIP 2015), model parameters under climate change, without or with adaptation, can be calculated, and the model can be used to evaluate the four Core Questions identified in Fig. 2.

The TOA-MD model was parameterized using household surveys conducted in 2011 with 160 farmers interviewed in 8 villages that provided data on farm, herd and household size, off-farm income, revenues from crops and livestock, and the costs of production. In addition, 8 focus group discussions, one per each village surveyed, assessed agricultural output and input prices, perceived as normal prices during the observation year, not peak prices (Homann-KeeTui et al. 2013, 2015). For the calculation of net returns, monetary values of the crop (grain and residues) and livestock (sale, draft power, manure, milk) outputs were estimated with observed values or at opportunity cost, with internally used crop and livestock outputs factored in as costs under the respective activities, taking into account the local user practices. For the analysis presented here, the farm households were stratified into three groups according to livestock ownership as the locally most important wealth criterion (none; $1-8$ cattle, or more than 8 cattle).

A Representative Agricultural Pathway (RAP) was developed with stakeholder collaboration to project the current systems into the future. In this analysis, the optimistic assumption was made that Zimbabwe will move out of 15 years of economic crisis towards positive economic development. Acknowledging the challenges and time required for institutional change, pro-active governance and investments, conservative projections were made for future productivity trends and prices. The pathway used was based on growth through market-oriented crop and livestock production, as government seeks to promote agricultural production and restore investor confidence. Severe liquidity constraints however restrict public and private investments. Limited employment opportunities in urban areas reduce rural-urban migration. An exogenous yield increase of $40 \%$ was assumed for maize as the predominant crop, and 35\% increase for small grains and legumes. Fodder crops were only recently introduced and no market exists, and no increase was assumed. Productivity increases of $35 \%$ for cattle and $25 \%$ for small stock offtake was assumed, made possible by reducing mortality and improving livestock quality, and also modest $10 \%$ increases milk, manure and draft power production were assumed.

It was also assumed that international product prices are not fully transmitted to the national and local markets. Price increases for grain and live animal sales was assumed to be $10 \%$ from 2005 to 2050, and a 5\% increase for the other products that are usually not traded. Input prices tend to remain high with $10 \%$ price growth. Input subsidies are assumed to be limited to vulnerable households during recovery and rehabilitation. 


\subsection{Impact of Climate Impact and Adaptation on Crop and Livestock Productivity}

The mean of the crop model simulations showed projected crop yield losses under the current farming practices were modest, in the range of 7-9\%, although some climate model projections were much higher or lower (Fig. 6). Crop systems in Nkayi are low
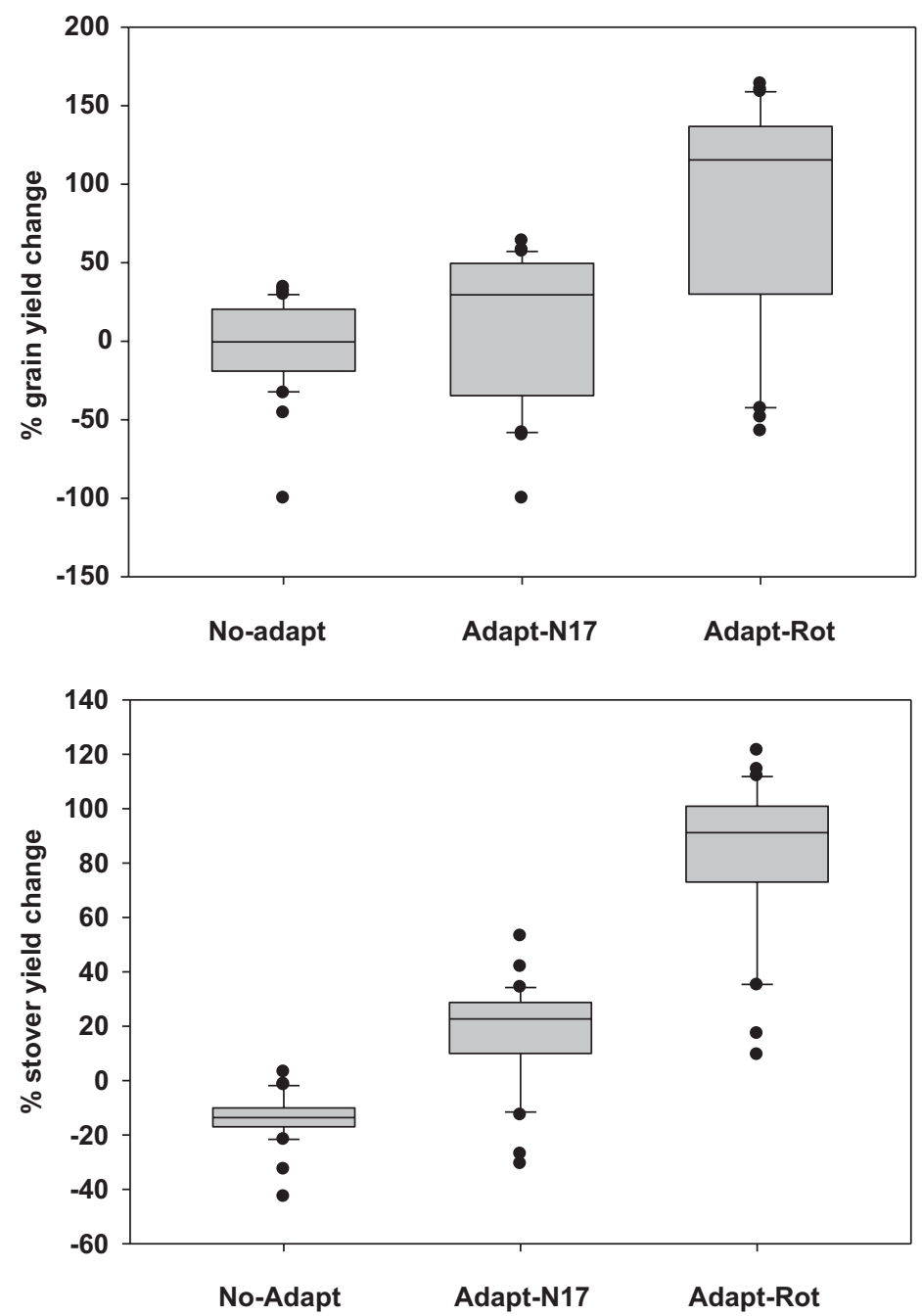

Fig. 6 Boxplots showing average percent maize grain and stover yield change in Nkayi district, Zimbabwe, under current farmer practice (no-adapt) and different adaptation strategies (Adapt-N17 $=$ microdosing at $17 \mathrm{~kg} \mathrm{~N} / \mathrm{ha}$ and Adapt-Rot $=$ maize-mucuna rotation system. The percent change under adapted scenarios is calculated with respect to the non-adapted scenario under climate change while for the non adapted scenario yield change is relative to current practice under current climate 
input systems where average yields are around 500-700 kg/ha. Temperature thresholds for maize in the APSIM model are greater than $30{ }^{\circ} \mathrm{C}$ (Hatfield et al. 2011; Hatfield and Prueger 2015), and current average maximum temperature during the growing season is about $27^{\circ} \mathrm{C}$, so higher average temperatures of $2-3{ }^{\circ} \mathrm{C}$ do not substantially affect crop production unless there are more extreme events in a particular growing season. The simulations show average impacts on yields are small but some larger positive and negative outcomes can also be expected (Fig. 6).

Because the average reductions predicted by the crop models are relatively small, the use of soil amendments as adaptation strategies can more than offset the negative impact of climate change, with mean yield gains ranging between $20 \%$ and $80 \%$ (Fig. 6). The use of organic amendments such as legume residues and low inorganic fertilizer application show higher yield variability as compared to the noadaptation scenario, however average yields under adapted management are greater than $2 \mathrm{t} / \mathrm{ha}$. The subsequent maize crop after mucuna would benefit from biological nitrogen fixation and also from the crop residues that are applied. Such adaptation strategies would benefit resource-poor farmers to improve main staple crop yields with minimal external inputs. Again, we emphasize that the analysis assumes that these changes in management would not be made as part of the ongoing improvement in practices that is represented in the RAP.

Impacts of climate change and adaptation packages on livestock productivity were assessed through changes in feed quantity and quality. Reduced grass growth due to climate change lowered feed intake from the rangelands by $10 \%$ and $50 \%$ in the rainy season and dry season respectively. Climate change reduced on-farm maize stover yield by on average $15 \%$, further aggravating the dry season feed gaps that are characteristic for the mixed crop-livestock systems in semi-arid areas. The adaptation package helped offsetting the adverse effects of climate change on fodder availability by increasing the fodder quantity through fertilizer input and rotations with legume crops. The diversification with legume grain and fodder crops also improved the fodder quality, primarily through higher protein content.

Climate change resulted in a 35-39\% and 30-35\% reduction of annual milk production for households with small and large herds respectively (Fig. 7). Offtake was roughly halved by climate change (Fig. 7) and with lower feed availability resulting in underfed animals, mortality rates rose by $8 \%$ and $14 \%$ for households with small and large herds respectively. With the adaptation package, on-farm feed quantity and quality was improved, resulting in milk production at roughly the same level that was obtained without climate change. The offtake was brought back to about $80 \%$ and $90 \%$ of the offtake in the current climate for households with small and large herds respectively.

\subsection{Economic Analysis: Climate Impact, Adaptation, Vulnerability and Resilience}

Table 2 summarizes the results of the economic analysis of climate change impact for the farm population in Nkayi stratified by cattle ownership. We compare climate change impact without adaptation and with the adaptation package (comprised of 

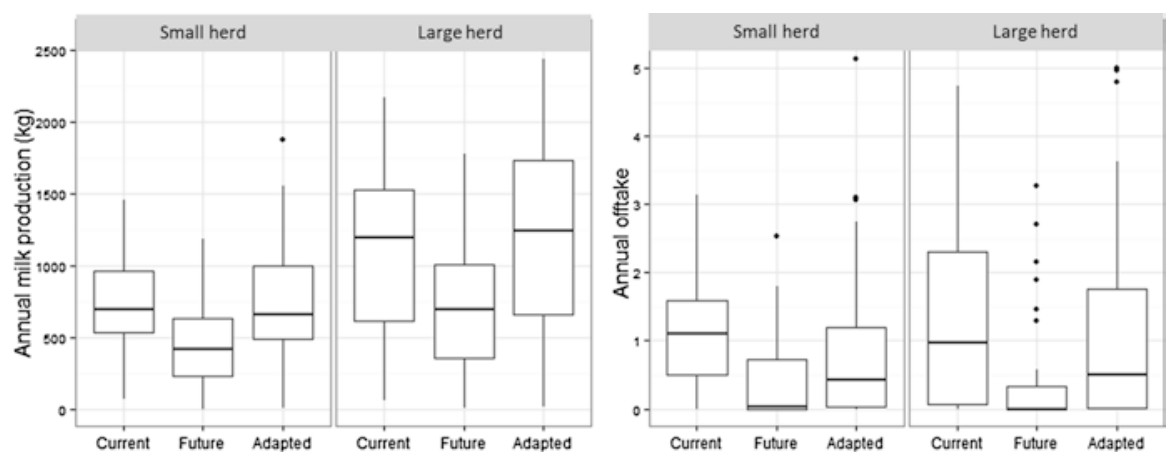

Fig. 7 Annual milk production and offtake per farm in the current and future climate without adaptation package and with the adaptation package (long duration maize varieties, allocation of land to a maize-mucuna rotation, mucuna biomass left on the fields as inorganic fertilizer for subsequent maize, and use of micro-dosing of $\mathrm{N}$ on maize) for households with small and large herds

the elements identified above: long duration maize varieties, allocation of land to a maize-mucuna rotation, mucuna biomass left on the fields as inorganic fertilizer for subsequent maize, and use of micro-dosing of $\mathrm{N}$ on maize in the maize-mucuna rotation). We emphasize that these results are based on a single scenario comprised of one climate model projection, one crop model and livestock model, and one socio-economic scenario, to illustrate the type of analysis that can be done. More generally, it is important to consider the uncertainties in each component by utilizing a range of scenarios and model assumptions.

Without adaptation, Table 2 shows that vulnerability to loss from climate change ranges from $45 \%$ of the farm households without cattle, to $61 \%$ and $71 \%$ of households with small and large herds. The households with cattle are more vulnerable because, as discussed above, the main adverse impact shown by the crop and livestock model simulations is on livestock feed availability and livestock productivity. These losses range from $25 \%$ to $57 \%$ of mean farm net returns before climate change, and thus represent a substantial loss for the vulnerable households, and correspond to losses of $11-16 \%$ of per capita income. However, some farms gain, and these gains range from $28 \%$ to $34 \%$ of mean returns before climate change. These gains are attributed to the heterogeneity in the bio-physical and economic conditions that exist. For example, in any given year, rainfall varies across the landscape with some areas drier and some wetter, with corresponding variation in crop and forage productivity. The net impacts aggregated across all farms are small for farms without livestock (about $+3 \%$ ), but much larger and negative for farms with large herds $(-23 \%)$. It is important to recognize that even though the losses are a larger percent of farm income for the farms with cattle, the farms without cattle are much poorer. Thus, with climate change the negatively impacted farms without cattle will be in an even worse condition than before climate change and much poorer than the farms with cattle.

Table 2 shows that farms without cattle are very likely to adopt the adaptations being considered, with adoption rates about $96 \%$ in the rapid adaptation scenario and over $75 \%$ in the scenario of a transitional adaptation in which the benefits are 
Table 1 Base system characteristics of 160 mixed farms used for the analysis, by farm type, in Nkayi district

\begin{tabular}{|c|c|c|c|c|c|c|}
\hline Variables & Units & 0 cattle & $1-8$ cattle & $>8$ cattle & Total & \\
\hline & & Mean & Mean & Mean & Mean & Std. Dev. \\
\hline $\begin{array}{l}\text { Proportion in } \\
\text { community }\end{array}$ & $\%$ & 42.5 & 38.1 & 19.4 & n.a. & n.a. \\
\hline Household members & people & 5.9 & 6.9 & 7.4 & 6.6 & 2.5 \\
\hline $\begin{array}{l}\text { Proportion of female } \\
\text { headed households }\end{array}$ & $\%$ & 27.9 & 31.1 & 22.6 & 28.1 & n.a. \\
\hline Net returns maize & US\$/farm & 60 & 162 & 63 & 100 & 121 \\
\hline Net returns other crops & US\$/farm & 31 & 62 & 35 & 44 & 53 \\
\hline Net returns cattle & US\$/farm & 0 & 472 & 1347 & 443 & 586 \\
\hline $\begin{array}{l}\text { Net returns other } \\
\text { livestock }\end{array}$ & US\$/farm & 9 & 19 & 15 & 14 & 29 \\
\hline Off-farm income & US\$/farm & 220 & 300 & 294 & 265 & 217 \\
\hline Farms with maize & $\%$ & 98.5 & 100.0 & 100.0 & 100.0 & 0.1 \\
\hline Maize area & $\mathrm{Ha}$ & 1.1 & 1.4 & 1.8 & 1.3 & 0.8 \\
\hline Maize grain yield & $\mathrm{kg} / \mathrm{ha}$ & 497 & 826 & 675 & 657 & 531 \\
\hline Farms with small grains & $\%$ & 23.5 & 32.8 & 41.9 & 30.6 & 46.2 \\
\hline Small grain area & $\mathrm{Ha}$ & 0.7 & 0.7 & 1.0 & 0.8 & 0.8 \\
\hline Small grain yield & $\mathrm{kg} / \mathrm{ha}$ & 393 & 726 & 327 & 512 & 622 \\
\hline Farms with legumes & $\%$ & 33.8 & 49.2 & 48.4 & 42.5 & 49.6 \\
\hline Legume area & ha & 0.4 & 0.4 & 0.5 & 0.4 & 0.3 \\
\hline Legume yields & $\mathrm{kg} / \mathrm{ha}$ & 452 & 722 & 388 & 557 & 541 \\
\hline Cattle $^{a}$ & TLU & 0 & 5.4 & 13.9 & 4.7 & 4.7 \\
\hline Other livestock $^{\mathrm{a}}$ & TLU & 0.3 & 0.5 & 1.6 & 0.6 & 0.9 \\
\hline
\end{tabular}

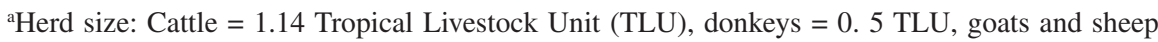
$=0.11 \mathrm{TLU}$

realized more gradually over 10 years. Farms without livestock would gain more (as a percent of their base system farm income) than farms with cattle, but do not necessarily gain more in absolute terms because the farms without livestock have much lower incomes (Table 1). The relatively smaller impact of climate change and greater benefit from adaptation for farms without livestock is because these adaptations improve crop productivity more than livestock productivity (Fig. 6). The adaptations have substantial impacts on per capita incomes, more than doubling the farm incomes of the poorest households.

For analysis of resilience, we considered two versions of the adaptation scenarios, a transitional case in which adaptation takes 10 years for farmers to realize the full benefits of the practices (e.g., due to a gradual dissemination of the technology and information), and a rapid case in which farmers realize the full benefits immediately. Recall that we defined resilience as the degree to which a system can be adapted to minimize the losses of climate change. In the analysis presented in Table 2, we interpret the rapid adaptation as the smallest possible loss, so its resilience is $100 \%$, and we evaluate the no-adaptation case and the transitional adaptation case relative to the 
Table 2 Future (2050) farming system vulnerability and resilience, and net economic impacts of climate change, for crop-livestock systems in Nkayi, Zimbabwe, for no adaptation, transitional adaptation and rapid adaptation scenarios, hot dry GCM (all values are percent)

\begin{tabular}{l|l|l|l|l|l|l|l|l}
\hline & & & \multicolumn{3}{|c|}{ Climate impact on net returns } & \multicolumn{2}{l}{$\begin{array}{l}\text { Adoption of } \\
\text { adaptations }\end{array}$} \\
\hline Stratum & Adaptation & Vulnerability & Gains & Losses & $\begin{array}{l}\text { Net } \\
\text { impact }\end{array}$ & Resilience & $\begin{array}{l}\text { Adoption } \\
\text { rate }\end{array}$ & $\begin{array}{l}\text { Adopter } \\
\text { gain }\end{array}$ \\
\hline No cattle & None & 45 & 28 & -25 & 3 & 91 & n.a. & n.a. \\
\hline No cattle & Transition & 18 & 73 & -32 & 41 & 93 & 75 & 60.5 \\
\hline $\begin{array}{l}\text { No cattle } \\
\text { Rmall } \\
\text { herd }\end{array}$ & None & 61 & 139 & -20 & 119 & 100 & 96 & 136 \\
\hline $\begin{array}{l}\text { Small } \\
\text { herd }\end{array}$ & Transition & 39 & 32 & -41 & -9 & 79 & n.a. & n.a. \\
\hline $\begin{array}{l}\text { Small } \\
\text { herd }\end{array}$ & Rapid & 25 & 42 & -33 & 9 & 93 & 80 & 20 \\
\hline $\begin{array}{l}\text { Large } \\
\text { herd }\end{array}$ & None & 71 & 34 & -57 & -23 & 79 & n.a. & n.a. \\
\hline $\begin{array}{l}\text { Large } \\
\text { herd }\end{array}$ & Transition & 46 & 47 & -42 & 5 & 98 & 64 & 43 \\
\hline $\begin{array}{l}\text { Large } \\
\text { herd }\end{array}$ & Rapid & 42 & 48 & -40 & 8 & 100 & 80 & 87 \\
\hline
\end{tabular}

Note: Transitional adaptation occurs over 10 growing seasons. Rapid adaptation occurs in the first growing season. Gains, Losses, Net Impact and Adopter Gain are percent of base system net returns.

rapid adoption case. The analysis considers the benefits over a 10 -year period using a discount rate of $10 \%$.

With these assumptions, the no-adaptation scenario gives the farms without cattle a resilience of $91 \%$, somewhat higher than the resilience of the systems with cattle (79\%). With transitional adaptation, the farms without livestock improve from $91 \%$ to $93 \%$, whereas the farms with livestock improve from $79 \%$ to $93 \%$ (small herds) and 98\% (large herds). Table 2 also shows that with rapid adaptation more farmers would adopt and the benefits would be much larger, especially for the small farms without livestock. This analysis illustrates the potential benefits of enhancing the adaptive capability of farmers, enabling them to substantially reduce vulnerability and enhance resilience when effective adaptation options are available.

\section{Conclusions}

In this chapter we described and demonstrated the use of new simulation-based technology impact assessment methods, developed by AgMIP, to evaluate the potential for currently available or prospective agricultural systems to achieve the 
goals of CSA. We described methods used to quantify the vulnerability and resilience of agricultural systems, two key elements of CSA. We used a case study of crop-livestock systems in Zimbabwe to illustrate how these methods can be used to evaluate alternative management practices for climate smart agriculture.

Our analysis of the Zimbabwe case illustrates the potential for these methods to test the usefulness of specific modifications to raise incomes, reduce vulnerability to climate change and to enhance resilience. While we must caution against generalizing from this single example, we do think that it illustrates the potential importance of making improved technologies available but also the role that adaptive capacity will play. This example also serves to demonstrate why it is important to clearly define the "simulation experiment," i.e., the conditions under which climate impacts and adaptations are being evaluated. In this example, it was assumed that there would be relatively little change in productivity over time, and that a package of improved practices that we called "climate adaptations" could provide higher incomes for many of the farmers. However, one could ask why these improvements are considered "climate adaptations" and what changes in the institutional or policy environment would be needed to facilitate their use. Thus, for a meaningful analysis of CSA, or climate adaptation more generally, these policy dimensions of the story must be addressed. Otherwise, the type of analysis we have presented here risks overstating the potential for adaptations to offset the potentially adverse effects of climate change.

Although we have not discussed mitigation of greenhouse gases in this chapter, it is important to note that the framework presented here can also incorporate greenhouse gas emissions as part of a technology assessment. Examples of how this modeling framework can be used for that purpose are presented in a number of publications, including Antle and Stoorvogel (2008). However, it should be noted that accurate quantification of greenhouse gas emissions, including changes in soil carbon, nitrous oxide emissions from soils, and methane emissions from livestock, is data-intensive and requires the use of complex models. Alternatively, estimates of average rates of emissions under alternative practices could be used. This is an area in need of further research.

Another area that clearly needs additional research is the incorporation of livestock herd dynamics and the interaction of crop and livestock systems. This is particularly important for smallholder farm households whose livelihoods and well-being depend on livestock both as a source of food and income as well as an asset that can be used to cope with climate variability and extremes. Further work on the role of livestock and crop-livestock systems in the context of climate smart agriculture is clearly warranted.

\section{References}

Agricultural Model Inter-comparison and Improvement Project (AgMIP) Guide for Regional Integrated Assessments: Handbook of Methods and Procedures, Version 6.0 (2015). http:// agmip.org. 
Antle J (2011) Parsimonious Multi-dimensional Impact Assessment. Amer. J. Agr. Econ. 93(5):1292-1311. doi:10.1093/ajae/aar052

Antle JM, SM Capalbo (2010) Adaptation of Agricultural and Food Systems to Climate Change: An Economic and Policy Perspective. Applied Economic Perspectives and Policy 32:386-416.

Antle JM, JJ Stoorvogel, RO Valdivia (2006) Multiple Equilibria, Soil Conservation Investments, and the Resilience of Agricultural Systems. Environment and Development Economics 11(4):477-492.

Antle JM, J Stoorvogel, R Valdivia (2014) New Parsimonious Simulation Methods and Tools to Assess Future Food and Environmental Security of Farm Populations. Philosophical Transactions of the Royal Society B. doi: 369:20120280

Antle JM, RO Valdivia, KJ Boote et al (2015b) AgMIP's Trans-disciplinary Agricultural Systems Approach to Regional Integrated Assessment of Climate Impact, Vulnerability and Adaptation. In: Rosenzweig C, D Hillel (eds) Handbook of Climate Change and Agroecosystems: The Agricultural Model Intercomparison and Improvement Project Integrated Crop and Economic Assessments, Part 1. Imperial College Press, London.

Bossio D (2009) Livestock and water: understanding the context based on the 'Compressive Assessment of Water Management in Agriculture'. The Rangeland Journal 31 (2):179-186.

Folke, C. (2006). Resilience: The emergence of a perspective for social-ecological systems analyses. Global Environmental Change, 16, 253-267. doi:10.1016/j.gloenvcha.2006.04.002

Hallegate, S. 2014. Economic Resilience: Definition and Measurement. Policy Research Working Paper 6852, The World Bank.

Hatfield, J.L., K.J. Boote, B.A. Kimball, L.H. Ziska, R.C. Izaurralde, D. Ort, A.M. Thomson, and D.W. Wolfe.2011. Climate impacts on agriculture: Implications for crop production. Agron. J. 103:351-370. doi:10.2134/agronj2010.0303

Hatfield, J. L. and Prueger, J.H. 2015. Temperature extremes: Effect on plant growth and development. Weather and climate extremes. 10. A. 4-10. doi: org/10.1016/j.wace.2015.08.001

Homann-KeeTui, S., D. Valbuena, P. Masikati, K. Descheemaeker, J. Nyamangara, L. Claessens, O. Erenstein, A. van Rooyen, D. Nkomboni. 2015. Economic trade-offs of biomass use in croplivestock systems: Exploring more sustainable options in semi-arid Zimbabwe. Agricultural Systems 134:48-60.

Homann, S., van Rooyen, A., Moyo, T., Nengomasha, Z., 2007 Goat production and marketing: Baseline information for semi-arid Zimbabwe. International Crops Research Institute for the Semi-Arid Tropics, pp84

Homann-KeeTui, S., Bandason, E., Maute, F., Nkomboni, D., Mpofu, N., Tanganyika, J., Van Rooyen, A. F., Gondwe, T., Dias, P., Ncube, S., Moyo, S., Hendricks, S., Nisrane, F. 2013. Optimizing Livelihood and Environmental Benefits from Crop Residues in Smallholder CropLivestock Systems in Southern Africa. ICRISAT Socio-economics Discussion Paper Series. Series Paper Number 11.

Kandji, T. S., Verchot, L., and Mackensen, J. 2006. Climate change and variability in Southern Africa: Impacts and adaptation in the agricultural sector, World Agroforestry Centre and United Nations Environment Programme Report, p. 42.

Kates, R.W., Travis, W.R., Wilbanks, T.J. 2012. Transformational adaptation when incremental adaptations toclimate change are insufficient. PNAS, 109:19, 7156-7161

Keating, BA., P.S. Carberry, G.L. Hammer, M.E. Probert, M.J. Robertson, D. Holzworth. 2003. An overview of APSIM, a model designed for farming systems simulation. European Journal of Agronomy 18: 267-288.

Lipper, L. P. Thornton, B.M. Campbell, T. Baedeker, A. Braimoh, M. Bwalya, P. Caron, A. Cattaneo, D. Garrity, K. Henry, R. Hottle, L. Jackson, A. Jarvis, F. Kossam, W. Mann, N. McCarthy, A. Meybeck, H. Neufeldt, T. Remington, P. Thi Sen, R. Sessa, R. Shula, A. Tibu, E.F. Torquebiau. 2014. Climate Smart Agriculture for Food Security. Nature Climate Change 4, 1068-1072.doi:10.1038/nclimate2437.

Malone, E.L. 2009. Vulnerability and Resilience in the Face of Climate Change: Current Research and Needs for Population Information. Battelle Pacific Northwest Division Richland, 
Washington 99352. http://www.globalchange.umd.edu/data/publications/Resilience_and_ Climate_Change.pdf. Accessed December 62015.

Masikati, P., S. Homann-KeeTui, K. Descheemaeker, O. Crespo, S. Walker, C.J. Lennard, L. Claessens, A.C. Gama, S. Famba, A.F. van Rooyen, and R.O. Valdivia. 2015. Crop-Livestock Intensification in the Face of Climate Change: Exploring Opportunities to Reduce Risk and Increase Resilience in Southern Africa by Using an Integrated Multi-modeling Approach. C. Rosenzweig and D. Hillel, eds. Handbook of Climate Change and Agroecosystems: The Agricultural Model Intercomparison and Improvement Project Integrated Crop and Economic Assessments, Part 2. London: Imperial College Press.

Masikati, P., 2011. Improving the Water Productivity of Integrated Crop-livestock Systems in the Semi-arid Tropics of Zimbabwe: Ex-ante Analysis Using Simulation Modeling. Ph.D. Thesis, ZEF, Bonn.

Morton, J. F. 2007. The impact of climate change on smallholder and subsistence agriculture, PNAS, 104(50), 19680-19685.

Nelson, G. C.; Valin, H.; Sands, R. D.; Havlik, P.; Ahammad, H.; Deryng, D.; Elliott, J.; Fujimori, S.; Hasegawa, T.; Heyhoe, E.; Kyle, P.; Lampe, M. V.; Lotze-Campen, H.; d'Cros, D. M.; van Meijl, H.; van der Mensbrugghe, D.; Muller, C.; Popp, A.; Robertson, R.; Robinson, S.; Schmid, E.; Schmitz, C.; Tabeau, A. \& Willenbockel, D. 2013. 'Climate change effects on agriculture: Economic responses to biophysical shocks', Proceedings of the National Academy of Sciences of the United States of America doi:10.1073/pnas.1222465110, 1-6.

Nelson, Donald R., W. Neil Adger, and Katrina Brown. 2007. "Adaptation to Environmental Change: Contributions of aResilience Framework."Annual Review of Environmentand Resources 32:395419. http://eprints.icrisat.ac.in/4245/1/AnnualReviewofEnvResources_32_395-419_2007.pdf

Rickards, L. and Howden, S. M. 2012. Transformational adaptation: agriculture and climate change. Crop \& Pasture Science, 63, 240-250., http://dx.doi.org/10.1071/CP11172

Rippke, U., Ramirez-Villegas, J., Jarvis, A., Vermeulen, S.J., Parker, L., Mer, F., Diekkrüger, B., Challinor, A.J. Howden, M. 2016. Timescales of transformational climate change adaptation in sub-Saharan African agriculture. Nature Climate Change Letters. I DOI: 10.1038/ NCLIMATE2947

Rosenzweig, C., J.W. Jones, J.L. Hatfield, J.M. Antle, A.C. Ruane and C.Z. Mutter. (2015). The Agricultural Model Intercomparison and Improvement Project: Phase I Activities by a Global Community of Science. C. Rosenzweig and D. Hillel, eds. Handbook of Climate Change and Agroecosystems: The Agricultural Model Intercomparison and Improvement Project Integrated Crop and Economic Assessments, Part 1. London: Imperial College Press.

Rosenzweig, C., A. Arslan, F. Matteoli, M. Ngugi, and T. Rosenstock. 2016. KAG Sub-Group on Integrated Planning and Monitoring for Climate-Smart Agriculture. (in preparation).

Rufino, M.C., J. Dury, P. Tittonell, M.T. Van Wijk, S. Zingore, M. Herrero and K.E. Giller. 2008. Collective management of feed resources at village scale and the productivity of different farm types in a smallholder community of North East Zimbabwe. Submitted to Agric. Syst.

Rufino, M.C., Herrero, M., van Wijk, M.T., Hemerik, L., de Ridder, N., Giller, K.E., 2009. Lifetime productivity of dairycows in smallholder farming systems of the highlands of Central Kenya. Animal 3, 1044-1056

Rufino, M.C., Dury, J., Tittonell, P., van Wijk, M.T., Herrero, M., Zingore, S., Mapfumo, P. and Giller, K.E. (2011). Competing use of organic resources village-level interactions between farm types and climate variability in a communal area of NE Zimbabwe, Agric. Syst. 104, 2011, 175-190.

Valdivia, R.O., J.M. Antle, C. Rosenzweig, A.C. Ruane, J. Vervoort, M. Ashfaq, I. Hathie, S. Homann-KeeTui, R. Mulwa, C. Nhemachena, P. Ponnusamy, H. Rasnayaka and H. Singh. (2015). Representative Agricultural Pathways and Scenarios for Regional Integrated Assessment of Climate Change Impact, Vulnerability and Adaptation. C. Rosenzweig and D. Hillel, eds. Handbook of Climate Change and Agroecosystems: The Agricultural Model Intercomparison and Improvement Project Integrated Crop and Economic Assessments, Part 1. London: Imperial College Press. 
Williams, T. O., Thornton, P., Fernandez-Rivera, S., (2002). Trends and prospects for livestock systems in the semi-arid tropics of Sub-Saharan Africa. In Targeting Agricultural Research for Development in Semi-Arid Tropics of Sub-Saharan Africa. Proceedings held at International Center for Research in Agroforestry Nairobi, Kenya from 1 to 3 July 2002, pp155-172

World Bank (2009). Making development climate resilient: A World Bank strategy for SubSaharan Africa, Report No. 46947 - AFR.

Open Access This chapter is distributed under the terms of the Creative Commons AttributionNonCommercial-ShareAlike 3.0 IGO license (https://creativecommons.org/licenses/by-nc-sa/3.0/ igo/), which permits any noncommercial use, duplication, adaptation, distribution, and reproduction in any medium or format, as long as you give appropriate credit to the Food and Agriculture Organization of the United Nations (FAO), provide a link to the Creative Commons license and indicate if changes were made. If you remix, transform, or build upon this book or a part thereof, you must distribute your contributions under the same license as the original. Any dispute related to the use of the works of the FAO that cannot be settled amicably shall be submitted to arbitration pursuant to the UNCITRAL rules. The use of the FAO's name for any purpose other than for attribution, and the use of the FAO's logo, shall be subject to a separate written license agreement between the FAO and the user and is not authorized as part of this CC-IGO license. Note that the link provided above includes additional terms and conditions of the license.

The images or other third party material in this chapter are included in the chapter's Creative Commons license, unless indicated otherwise in a credit line to the material. If material is not included in the chapter's Creative Commons license and your intended use is not permitted by statutory regulation or exceeds the permitted use, you will need to obtain permission directly from the copyright holder.

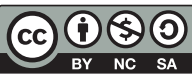

